\title{
A REVIEW ON NOVEL APPROACHES INCORPORATED IN THE FORMULATION OF GASTRO RETENTIVE DRUG DELIVERY SYSTEM
}

\author{
Nazia Khanam, 1 , Md Irshad Alam², S Shariq Mian³, N Srinivas ${ }^{1}$ \\ ${ }^{1}$ Department of Pharmaceutics, Malla Reddy Institute of Pharmaceutical Sciences, Hyderabad, India. \\ ${ }^{2}$ Reference Standards Laboratory Department, United States Pharmacopeia (P) Ltd, Hyderabad, India. \\ ${ }^{3}$ Department of Pharmacy, I.F.T.M. University, Moradabad, India.
}

\begin{abstract}
*Corresponding Author Email: nazia.khanam7@gmail.com
ABSTRACT

Gastro retentive drug delivery system (GRDDS) is one of the most widely used technique of drug formulation for oral controlled delivery of drugs. These formulations help to prolong the gastric residence time, leading to increased contact time of drug with the gastric mucosa, therefore better bioavailability is attained and hence increased therapeutic activity. Various types of GRDDS systems are available based on their floating and nonfloating behavior, different polymers were used to develop these gastro retentive systems. Individual systems had some deficiencies, they were tried to be eliminated by advanced formulation techniques that includes combination of two or more GRDDS in one design. It was observed that the latest combinational approaches lead to formulation of improved and effective drug delivery systems with better patient acceptability.
\end{abstract}

\section{KEY WORDS}

Gastric Residence Time (GRT), Polymer, Bioavailability, Mucoadhesion.

\begin{abstract}
INTRODUCTION
The main objective of all the drug delivery systems is to provide therapeutic amount of drug at specific site in the body to achieve and maintain optimum therapeutic concentrations in the body and exhibit desired pharmacological action with minimum adverse effects. This objective is achieved by maintaining optimum dosing frequency with desirable route of administration.[1] Route of administration plays a vital role in drug release and its effectiveness, instead of various advancements in drug delivery system, till today oral route is the most preferred route to due to the ease of administration, economical, patient compliance and flexibility in formulation. Among drugs, solid oral dosage forms represents the preferred class of products.[2-5] It is well known fact that, it is important to take medication several times for the treatment of ailments, this may lead to fluctuating drug level in body, to prevent frequent drug administration and maintain therapeutic drug level in body it is essential to administer drug by controlled release system. Various
\end{abstract}

oral controlled release dosage forms were developed to achieve maximum therapeutic effectiveness.[6,7] Oral controlled release drug delivery system had various advantages like the drug release rate was predetermined, predictable and controlled, still there were drawbacks with some drugs that showed poor bioavailability due to incomplete absorption or degradation in the gastro intestinal tract. There are certain drugs that are absorbed from specific sites and they require release at that particular site only for better absorption.[8] In designing of oral controlled release system, the most important physiological factor that is to be considered is gastric residence time (GRT), as it is responsible for the reduction in efficacy of therapeutic agent. GRT affects the bioavailability of dosage forms along with variable and short gastric emptying time, it is also influenced by fasting as well as fed states of the stomach. In order to regulate the location of drug release from the delivery system particularly for those drugs that shows an absorption window in the GI tract or drugs with a stability problem, 
in a specific region of the Gl tract and to prolong the $\mathrm{GRT}$, led to the development of oral controlled-release dosage forms possessing gastric retention capabilities. These formulated dosage forms are known as Gastroretentive drug delivery system which has the capability to couple GRT with drug release for extended time period. [9-17] Gastro-retentive drug delivery system (GRDDS) can be defined as a system that retains in the stomach for a sufficient time interval against all the physiological barriers, releasing its active medicament in a controlled manner, and finally metabolized in the body. Along with systemic effect, GRDDS has been used locally to treat gastric and duodenal ulcers, including esophagitis, by eradicating the deeply buried Helicobacter pylori from the sub mucosal tissue of the stomach.

\section{Gastro retentive Dosage Form}

These formulations can reside in the gastric region for several hours and thus, prolong the gastric residence time of the drugs, on oral administration these dosage forms are retained in the stomach and releases the drug in a controlled and sustained manner so that the drug can be supplied continuously in the upper gastro intestinal tract. This prolonged gastric retention enhances bioavailability, decreases drug wastage, and improves solubility of drugs that are less soluble at high pH environment. $[18,19]$

\section{Ideal characteristics of drugs for GRDDS}

Drug molecules that have poor colonic absorption but have improved absorption at upper region of gastro intestinal tract are desirable candidates for the formulation of GRDDS. Identification of physical, chemical and biological properties of the drug should be determined before development of GRDDS. Biopharmaceutical parameters also play a vital role in delivery of a drug through GIT. Excipients also play an important role in formation of a drug delivery system, so, it is essential to perform the compatibility study between drug and excipients or between selected excipients. Examples of drugs that are suitable to be designed as GRDDS: Misoprostol, Diazepam, Captopril etc.[20-24]

\section{Advantages of Gastroretentive Drug Delivery Systems}

1. GRDDS helps to maintain a constant therapeutic level of drug for longer period of time, example Beta lactam antibiotics.

2. These controlled release formulations of drugs with short half life, decreases dosing frequency, hence improves patient compliance.

3. Therapeutic efficiency of drug is enhanced.[25]

4. They reduce mucosal irritation of drugs, by releasing drug slowly at a controlled rate, for example non steroidal anti-inflammatory drugs.

5. As the counter activity of the is reduced, higher drug efficiency is obtained.[26]

6. Enhanced bioavailability is attained.[27]

7. GRDDS is a means to achieve targeting of drugs at specific site.[28]

8. This drug delivery system has wide application in chronotherapy.[29,30]

\section{Limitations of Gastroretentive Drug Delivery System} $[31,32]$

1. GRDDS is not suitable for those drugs that are unstable in acidic environment or those have less acid solubility or that can cause gastric lesions.

2. Those drugs that undergo first pass metabolism are not favorable candidate.

3. Other limitations of GRDDS are violent gas generation, disintegration of dosage form, dose dumping, alkaline microenvironment etc.

4. Poor in vitro and in vivo correlation along with higher cost of formulation.

5. Drug retrieval is difficult in case of toxicity, poisoning or hypersensitivity reaction.

Polymers Used In Gastro retentive Drug Delivery System $[33,34]$

Alginates: Alginate is a naturally occurring biocompatible and biodegradable linear polysaccharide obtained from brown seaweed, widely used due to its good mucoadhesive property. It is a derived polysaccharide block composed of regions of sequential $\beta$-D-mannuronic acid monomers ( $M$-blocks), regions of $\alpha$-L- guluronic acid (G-blocks), and regions of interspersed $M$ and $G$ units. Mostly alginates are commercially available in the form of the salt, i.e. sodium alginate, which has a unique property of 
transformation from sol to hydrogel with more than $95 \%$ of water molecules held inside.[35-37] It is widely used in formulations due to gelation nature, Talwar and coworkers had developed a GRDDS of ciprofloxacin containing sodium alginate, xanthum gum, sodium bicarbonate and crosslinked polyvinyl pyrrolidone, found that a hydrated gel matrix that entrapped the gas, enabling the tablet to float and be retained in the stomach or upper part of the small intestine (spatial control). The hydrated gel matrix created a tortuous diffusion path for the drug, resulting in sustained release of the drug, it was observed that change in the percentage of sodium alginate showed unexpected improvement in the pharmacodynamic and pharmacokinetic parameters.[38]

Xanthan Gum: It is natural, biosynthetic, edible gum with extracellular polysaccharides, it consists of glucose, mannose and glucuronic acid. Xanthan is long chain polysaccharides with large number of trisaccharide side chain, it consists of $a b-(1,4)-D$ glucose backbone. xanthan gum develops a weak structure in water that leads to formation of high viscosity at low concentration, it is highly soluble in cold and hot water and this behavior is related to polyelectrolyte nature of the xanthan molecule. Xanthan gum is mainly considered to be non-gelling and used for viscosity.[39] Mohammed Muqtader et al had developed a buoyant delivery systems using xanthan gum and guar gum for the enhancement of bioavailability by increasing the GRT of famotidine, that has higher absorption at lower pH.[40]

Carbopol: Carbopol is very high molecular weight polymers of acrylic acid, widely used for their mucoadhesive properties. Among various formulations containing carbopol, one developed by Nur and Zhang that includes floating tablets of captopril using HPMC (4000 and 15,000 cps) and carbopol 934P. The buoyancy studies revealed that tablets remained floating for 24 hours, it was concluded that the buoyancy of the tablet was regulated by swelling of the hydrocolloid particles on the tablet surface when it came in contact with the gastric fluids and the presence of internal voids in the center of the tablet. A prolonged release floating system was formulated.[41,42]

Chitosan: chitosan is linear polysaccharide consisting ofdifferent amounts of $\beta$-(1 $\rightarrow 4)$-linked 2 -amino-2-
deoxy-B-D-glucopyranose(GIcN) and 2-acetamido-2deoxy- $\beta$-D-glucopyranose (GlcNAc) residues.[43] Normally it is insoluble in aqueous solutions above $\mathrm{pH} 7$ but in dilute acids, the protonated free amino group enhances aqueous solubility. Ishak RA and co-workers formulated GRDDS of metronidazole in chitosantreated alginate beads by incorporating ionotropic gelation method using factorially designed in which three viscosity- imparting polymers namely, methyl cellulose, carbopol 934P and carrageenan were used for treatment of $\mathrm{H}$. pylori-infection. It was observed that floating alginate beads gave better result in treatment as compared with corresponding suspension form, regarding eradication of $\mathrm{H}$. pylori infection. $[44,45]$

Polyvinyl alcohol (PVA): It is prepared from polyvinyl acetate through hydrolysis, easily degradable by biological organisms and it is a solubilized crystalline structured polymer in water.[46] It is used with other natural polymers due to its film forming property. lannuccelli and co-worker prepared a multiunit system consisting of calcium alginate core and calcium alginate/PVA membrane, both separated by an air compartment, in presence of water, the PVA leaches out and increases the membrane permeability, therefore it maintained the integrity of the air compartment. It was observed that with increase in molecular weight and concentration of PVA, there was an increase in flow properties of the system. $[47,48]$

Eudragit: It is Ethacrylic acid copolymer USP, comprises of Ethyl acrylate, methyl methacrylate and a low content of methacrylic acid ester with quaternary ammonium groups. The ammonium groups are present as salts and make the polymer permeable, it has bio adhesive properties, the two forms widely used are eudragit ${ }^{\circledR}$ । 100 and eudragit ${ }^{\circledR}$ s 100 . It has been found that different grades of eudragit can be combined to achieve the required GI drug targetting. El-Kamel and co-workers developed floating microparticulate system of ketoprofen, using emulsion solvent diffusion technique with four different ratios of Eudragit S100 with Eudragit RL. It was observed that the encapsulation efficiency decreased with increase in Eudragit $\mathrm{RL}$ content.[49-51]

Ethyl cellulose: It is water insoluble and biocompatible polymer that has been used in the preparation of coated and matrix tablets, micro and nano capsules, 
beads and other coated solid pharmaceutical dosage forms, it is extensively used encapsulating material.[52,53] Patel et al, developed controlled release multiunit floating system of a highly watersoluble drug, ranitidine $\mathrm{HCl}$, the granules were prepared by melt granulation technique and evaluated for in vitro floating and drug release profile. EC, MC and HPMC were evaluated as release rate modifiers. It was found that the moderate amount of EC provides desired release of ranitidine hydrochloride from a floating system.[54]

\section{Approaches To Fabricate Gastro-Retentive System}

Gastro retentive drug delivery system can be broadly classified as floating and non-floating system.

\section{Floating drug delivery system}

It was first described by Davis in 1968, they are low density systems with sufficient buoyancy to float over the gastric contents and remain in the stomach for a prolonged period of time. As these system floats over the gastric contents, it slowly releases the drug with desired rate, which further leads to increased GRT and least fluctuations in plasma drug concentration.[55-58] In these designed dosage forms bulk density of the dosage form becomes less than the density of gastric fluid $(1.004$ to $1.010 \mathrm{~g} / \mathrm{ml})$ after a certain lag time, lag time depends on the rate of swelling of the polymer used in the formulation, that again depends on the type, viscosity grade, presence swelling enhancers, etc. These listed parameters are also responsible for the determination of period of flow along with in vitro drug release rate. Physiological conditions of the patients, like fed-state or fasting state, amount of gastric fluid, etc. also influences the efficiency of floating drug delivery system.[59] Floating drug delivery system is further divided as follows:

\section{Effervescent System}

In these floating devices the buoyancy in stomach can be achieved by incorporating a floating chamber-filled with vacuum, air or an inert gas. Gas can be introduced into the floating Due to volatization of organic solvents gas can be introduced into the floating chamber of GRDDS or by carbon di-oxide formation as a result of an effervescent reaction between organic acids and carbonate-bicarbonate salts. These floating devices contain a hollow deformable unit that converts from a collapsed to an expanded position and returns to its original collapsed position after predetermined amount of time to permit the continuous ejection of the inflatable system from the stomach.[60,61]

\section{Non-effervescent system}

These floating systems comprises of large quantities of one or more gel forming, highly swellable, cellulosic hydrcolloids, polysaccharides or matrix-forming polymers like polycarbophil, polymethacrylate, polyacrylates and polystyrene.[62] When administered orally, these floating dosage form swells, as soon as it comes in contact with the gastric fluids and obtains bulk density of less than one, due to the entrapped air it within the swollen matrix, the dosage form develops buoyancy. Therefore these swollen gel-like structures acts as a reservoir and allows controlled release of drug through the gelatinous mass. Superporous hydrogels are example of this type of delivery system.[63] Noneffervescent system are further classified as follows:

Hydrodynamically balanced system: It was first designed by Sheth and Tossounian in the year 1984.[64] These floating devises comprises of one or more gel forming hydrophilic polymers which on coming in contact with the gastric fluids swells and forms a colloidal gel barrier resulting in low density that helps to float on the stomach content. The continuous erosion of the surface allows water penetration to the inner layers, therefore maintains surface hydration and buoyancy of the delivery system.[65]

Microbaloons: These are also known as hollow microspheres, highly uploaded with drug in their outer shells of polymers, prepared by emulsion-solvent diffusion method. The ethanol: dichloromethane solution of the drug along with an enteric acrylic polymer was poured into an agitated aqueous solution of poly vinyl alcohol which was thermally controlled at 40 ㅇ , formation of gas phase occurs in the dispersed polymer by the evaporation of dichloromethane formed and an internal cavity in the microsphere of the polymer with drug. These formulated hollow microspheres floated continuously over the surface of an acidic dissolution media containing surfactant for more than 12 h. $[66,67]$

Alginate beads: Formulations comprising of alginate, led to a new technique of floating drug delivery system, using ionic gelation technique to form multi-unit 
floating spherical beads, due to its high entrapment rate.[68,69] Floating alginate beads of about $2.5 \mathrm{~mm}$ diameter were prepared from freeze dried calcium alginate, which was precipitated when sodium alginate solution was dropped into aqueous solution of calcium chloride The beads were then separated, snap-frozen in liquid nitrogen, and freeze-dried at -40 C for 24 hours, leading to the formation of a porous system, that remained buoyant in the stomach and gave a prolonged residence time of more than 5.5 hours.[70]

Microporous compartment: In this GRDDS, a drug reservoir is encapsulated within a microporous compartment along with pores at its top and bottom walls, due to the entrapped air within the floatation chamber the delivery system becomes buoyant and floats over the gastric content. Through these pores the gastric fluid enters, dissolves the drug and carries the dissolved drug in stomach and proximal part of the small intestine for absorption.[71]

\section{Non-floating drug delivery system}

These do not float in the stomach, they retain there by different mechanisms. Non-floating drug delivery system is further divided into:

\section{High Density Drug Delivery System}

These formulations were prepared by coating the drug moiety on a heavy core or by mixing with inert materials like barium sulfate, zinc oxide, iron powder and titanium oxide to increase the density of the formulation, more than the density of the normal gastric content. As these materials enhance the density up to $1.5-2.4 \mathrm{gm} / \mathrm{cm} 3$, it extends the GI transit time of formulation from an average of 5.8 to 25 hours. The major drawback associated with this system is its increased dose size required to obtain that high density level, also its effectiveness was not observed in human beings, therefore, no high density system formulation has been marketed.[72]

\section{Mucoadhesive system}

Mucoadhesive drug delivery systems are non-floating systems formulated to achieve gastric retention of drugs, these are prepared with various mucoadhesive polymers to get attach inside the lumen of the stomach wall and survive the gastrointestinal motility for a longer period, these are also beneficial as site specific drug absorption in infected area. GRT was extended by these systems, therefore improves bioavailability.
Examples of some mucoadhesive excipients are polycarbophil, lectins, carbopol, chitosan, carboxymethylcellulose (CMC), pectin etc.[73] There are various types of mucoadhesion like:

- Hydration-Mediated Adhesion.[74]

- Bonding-Mediated Adhesion.[75]

- Receptor-Mediated Adhesion.[76]

\section{Magnetic system}

This drug delivery system was designed to retain the dosage form within the stomach with the help of magnetic field, created by magnetically active elements within the dosage form. It was designed as such, that one external magnet was required to position on the abdomen over the location of the stomach to retain the administered drug in place, due to lack of patient compliance this delivery system was not encouraged further.[77]

\section{Unfoldable system}

These non-floating drug delivery systems comprises of various erodible and non-erodible polymers that are biodegradable with different geometrical shapes and are packed tightly into a gelatin capsule that unfolds in the gastric fluids and increases in size and it remains lodged at sphincter avoiding its exit from the stomach. The size of the dosage form should be small enough to be swallowed but unfold itself when it comes in contact with gastric fluid, and after a certain period of time its size should become small so that it will be easily evacuated.[78]

\section{Novel combinational techniques to fabricate GRDDS}

The combination of mucho adhesion and floating or swelling mechanism is being adopted as another novel approach for improved gastro-retention attributes, these combinational approaches are described as follows:

\section{Floating and mucoadhesion technology-based systems}

A combination of floating and non-floating system which was mucoadhesive system were formulated, to achieve maximum gastric retention attributes of dosage by floating on the gastric fluid and can also bind with the mucosal lining. From among various performed studies of dual technology of floating and mucoadhesion, one experimental study performed by Liu et al is described here.[79] They formulated hollow and mucoadhesive 
microspheres consisting of ethyl cellulose as the matrix, eudragit to regulate release rate and glycerylmonooleate as the mucoadhesive polymer. It was observed that the prepared dual technology based microspheres showed good floating along with enhanced mucoadhesion.

Swelling and mucoadhesive technology-based systems Sankar $\mathrm{R}$ et at had developed a gastro retentive formulation of acyclovir by combining swelling and mucoadhesive technique using different concentrations of carbomer and polyethylene oxide. It was observed from the result analysis that a targeted drug release profile was obtained alonf with excellent mucoadhesive strength, that gave prolonged GR time in upper gastrointestinal tract with improved bioavailability and patient compliance.[80]

\section{Swelling and floating technology-based systems}

Chen et al had fabricated a swellable and floatable system of losartan, the excipients comprises of hydroxyethyl cellulose, sodium carboxymethyl cellulose and sodium bicarbonate. The prepared formulation was evaluated for various parameters to test swelling and floating properties, it was observed that the formulation showed good swelling along with floating properties. Release of drug was $\mathrm{pH}$ dependent, increased bioavailability along with prolonged GRT was observed.[81]

Effervescence incorporated within swelling and floating-based system

When an additional feature of effervescence was incorporated within a swelling-based floating delivery system, it leads to better floating lag time along with improved floating time, it can be obtained by incorporation of various effervescent substances like sodium bicarbonate, tartaric acid and citric acid in a formulation. The prepared formulation obtains effective density that is less than the gastric fluid and results in an upward motion onto a dosage form which maintains the buoyancy for a prolonged period of time, along with the single unit systems, the bi-layers and trilayers design of this combination approach has also been considered to incorporate two different drugs with different release profiles.[82,83]

Table 1 - List of commercialized GRDDS of India.[84]

\begin{tabular}{lccc}
\hline \multicolumn{1}{c}{ Drug } & Technology & Product & Company \\
\hline Ferrous sulfate & Colloidal gel forming floating system & Conviron ${ }^{\circledR}$ & Ranbaxy, India \\
Ofloxacin & Gas generating floating tablets & Oflin OD $^{\circledR}$ & Ranbaxy, India \\
CiprofloxacinHCl & Floating tablets & Cifran OD & Ranbaxy, India \\
Rifaximin & Bioadhesive tablets & Xifaxan ${ }^{\circledR}$ & Lupin, India \\
Baclofen & Coated multi-layer floating and swelling system & Baclofen GRS $^{\circledR}$ & Sun Pharma, India
\end{tabular}

\section{CONCLUSION}

It has been observed that for oral drug delivery, gastro retentive drug delivery system has emerged as a boon for controlled delivery of drugs that exhibit absorption window along with their enhanced bioavailability. As it is known that to obtain maximum therapeutic benefit from certain drugs, it is essential to delay to their gastric residence time, various technical approaches had been formulated to achieve it. But no single gastro retentive system delivered all required features, so a combination of one or more floating and non-floating systems along with suitable excipients were selected to formulate such a dosage form that yields maximum therapeutic efficacy of drugs.

\section{REFERENCES}

[1] Bhoyar PK, Baheti JR and Burde VV. An overview of a gastro retentive floating drug delivery system. World Journal of Pharmaceutical research, 1(2): 22-40, (2012) 
[2] Lachman L, Liberman HA and Kanig JL. The theory and practice of industrial pharmacy, Lea \&Febiger, Philadelphia, 293, ISBN 0-8121-0977-982, (1986)

[3] Streube A, Siepmann J and Bodmeier R. Drug delivery to the upper small intestine window using gastro retentive technologies. Current Opinion in Pharmacology, 6:501508, (2006)

[4] Das PD, Text book of medicine.Current Book Internationals, 4:182-195, (2000)

[5] Stanley SD. Formulation strategies for absorption windows. Drug Discov Today, 10(4):249-257, (2005)

[6] Khanam N, Alam MI, Sachan AK, et al. Fabrication and evaluation of propranolol hydrochloride loaded microspheres by ionic-gelation technique. Der Pharmacia Lettre, 4(3):815-820, (2012)

[7] Hoffman A. Pharmacodynamic aspects of sustained release preparations. Adv Drug Deliv Rev, 33:185-189, (1998)

[8] Niranjanbhai BD, Mahendrakumar VN, Surendran CS et al. Advances in GRDDS: Raft forming system a review. Journal of Drug Delivery \& Therapeutics, 2:123-128, (2012)

[9] Shargel L, Andrew BC, Applied Biopharmaceutics and Pharmacokinetics. London: Prentice Hall Int , 4:112-25, (1999)

[10] Adibkia K, Hamedeyazdan S and Javadzadeh Y. Drug release kinetics and physicochemical characteristics of floating drug delivery systems. Expert Opin Drug Deliv ,8(7):891-903, (2011)

[11] Kaur B, Sharma S, Sharma G, et al. A Review of Floating Drug Delivery System. Asian Journal of Biomedical and Pharmaceutical Sciences, 3(24):1-6, (2013)

[12] Chen YC, Ho H, Lee TY, et al. Physical characterizations and sustained release profiling of gastroretentive drug delivery system with improved floating and swelling capabilities. International Journal Of Pharmaceutics, 44:162-169, (2013)

[13] Kumar R and Philip A. Gastroretentive dosage forms for prolonging gastric residence time. Int J Pharm Med 21:157-171, (2007)

[14] Sugihara H, Matsui Y, Takeuchi H,. et al. Development of a gastric retentive system as a sustained-release formulation of pranlukast hydrate and its subsequent in vivo verification in human studies. Eur J Pharm Sci, 53:62-68, (2014).

[15] Aoki H, Iwao Y, Mizoguchi M, et al. Clarithromycin highly loaded gastro-floating fine granules prepared by highshear melt granulation can enhance the efficacy of Helicobacter pylori eradication. Eur J Pharm Biopharm, 92:22-27, (2015)
[16] Kim JY, Bae HJ, Choi J, et al. Efficacy of gastro-retentive forms of ecabet sodium in the treatment of gastric ulcer in rats. Arch Pharm Res, 37:1053-1062, (2014)

[17] Adebisi AO, Laity PR and Conway BR. Formulation and evaluation of floating mucoadhesive alginate beads for targeting Helicobacter pylori. J Pharm Pharmacol, 67:511-524, (2015)

[18] Garg AK, Kapoor G and Sachdeva RK. Formulation and evaluation of nizatidine floating tablets. American Journal of pharmatech Research, 2(5):504-515, (2012)

[19] Kesarla RS, Vora PA, Sridhar BK, et al. Formulation and evaluation of floating tablet of $\mathrm{H} 2$-receptor antagonist. Drug Dev Ind Pharm, 41:1499-1511, (2015)

[20] Kagan $L$ and Hoffman A. Systems for region drug delivery in the gastrointestinal tract: biopharmaceutical considerations. Expert Opin Drug Deliv, 5(6):681-692, (2008)

[21] Strubing S, Metz H and Mader K. Characterization of poly(vinyl acetate) based floating matrix tablets. J Control Release, 126(2):149-155, (2008)

[22] Khan F and Dehghan M. Enhanced bioavailability of atorvastatin calciumfrom stabilized gastric resident formulation. AAPS Pharm Sci Tech, 12(4):1077-1086, (2011)

[23] Oth, M., et al., The bilayer floating capsule: a stomachdirected drug delivery system for misoprostol. Pharmaceutical research, 9(3): 298-302, (1992)

[24] Streubel A, Siepmann J and Bodmeier R, Floating microparticles based on low density foam powder. International journal of pharmaceutics, 241(2): 279-292, (2002)

[25] Singh BN and Kim KH. Floating drug delivery systems: an approach to oral controlled drug delivery via gastric retention. J. Control Release, 63:235-259, (2000)

[26] Deshpande AA, Shah NH, Rhodes CT, et al. Controlled Release Drug Delivery Systems for prolonged gastric residence; An overview, Pharm. Res, 22(6):531-539, (1996)

[27] Klausner EA, Lavy E, Friedman M, et al. Novel levodopa gastroretentive dosage form: in-vivo evaluation in dogs. Journal of Controlled Release, 88(1): 117-126, (2003)

[28] Hoffman A and Stepensky D, Pharmacodynamic aspects of modes of drug administration for optimiz ation of drug therapy. Critical Reviews ${ }^{\mathrm{TM}}$ in Therapeutic Drug Carrier Systems, 16(6):571-639, (1999)

[29] Smolensky MH and Peppas NA. Chronobiology, drug delivery, and chronotherapeutics. Adv Drug Deliv Rev 59:828-851, (2007)

[30] Roy $P$ and Shahiwala A. Statistical optimization of ranitidine $\mathrm{HCl}$ floating pulsatile delivery system for 
chronotherapy of nocturnal acid breakthrough. Eur J Pharm Sci, 37:363-369, (2009)

[31] Pawar VK, Kansal S, Asthana S, et al. Industrial Perspective of Gastroretentive Drug Delivery System: Physiochemical, Biopharmaceutical,Technological and regulatory considerations. Expert opinion on drug delivery, 9:551-565, (2012)

[32] Badoni A , Ojha A, Gnanarajani G, et al. Review on Gastro Retentive Drug Delivery System. The Pharma Innovation, 1(8): 32-42, (2012)

[33] Prajapati ST, Patel LD and Patel CN. Polymers for floating drug delivery system. Syst Rev Pharm, 2:1-7, (2011)

[34] Aslam R, Mehmood $Y$ and Khan S. Techniques and polymers used to design Gastroretentive drug delivery systems - a review.World journal of pharmacy and pharmaceutical sciences, 3(12): 970-110, (2014)

[35] Draget KI, SkjakBræk G and Smidsrod O. Trends in Biotechnol, 8:71-78, (1999)

[36] Stevens MM, Quanadilo HF, Langer R, et al. Biomaterials, 25:887-894, (2004)

[37] Tonnesen HH and Karlsen. J Drug Dev Ind Pharm, 28:621$630,(2002)$

[38] Talwar N, Sen H, Staniforth and JN. Orally administered controlled drug delivery system providing temporal and spatial control. US patent 6261601,2001

[39] Singh AK. Role of natural polymers used in floating drug delivery system. J Pharmaceutical \& Scientific Innovation, 1(3): 11-15, (2012)

[40] Muqtader M. Development of famotidine buoyant drug delivery system using natural polymers. Int J Biopharmaceutics, 3(1): 17-21, (2012)

[41] Wade A and Weller P. Hanbook of Pharmaceutical Excipients. American Pharmaceutical Association The Pharmaceutical Press, London :71-73, (1994)

[42] Nur AO and Zhang JS. Captopril floating and/or bioadhesive tablets, design and release kinetics. Drug Dev Ind Pharm, 26:965-969, (2000)

[43] Roberts GAF. Chitin Chemistry, 1st ed. MacMillan, London, UK, (1992)

[44] Muzzarelli RAA. Natural Chelating Polymers; Pergamon Press: New York, NY, USA: 83, (1973)

[45] Ishak RA, Awad GA, Mortada ND, et al. Preparation, in vitro and in vivo evaluation of stomach-specific metronidazole-loaded alginate beads as local antiHelicobacter pylori therapy. J Control Release, 119:207214, (2007)

[46] Razzak MT, Darwis D and Zainuddin S. Irradiation of polyvinyl alcohol and polyvinyl pyrrolidone blended hydrogel for wound dressing, Radiant Phys Chem, 62:107-113, (2001)
[47] Albdiry M, Yousif BF. Morphological structures and tribiological performance of unsatutated polyester based untreated/silane-treated halloysite nanotubes. Matter Des, 48:68-76, (2013)

[48] lannuccelli V. Air Compartment Multiple-Unit Systems for Prolonged Gastric Residence, Part I: Formulation Study. Int J Pharm, 174:47-54, (1998)

[49] Rowe RC, Sheskey PJ and Owen SC. In: Rowe, R. C. (Ed), Hand book of Pharmaceutical Excipients. Pharmaceutical press, Great Britain: 916-925,389393,432-433,132-134, (2006)

[50] Nikam VK. Eudragit a Versatile Polymer-A Review. Pharmacology online, 1:152-164, (2011)

[51] Kamel AH, Sokar MS, Al Gamal SS, et al. Preparation and evaluation of ketoprofen floating oral delivery system. Int J Pharm, 220:13-21, (2001)

[52] Reddy KR, Mutalik S and Reddy S. AAPS PharmSciTech, 4:E61, (2003)

[53] Basit AW, Podczeck F, Newton JM, et al. Eur J Pharm Sci, 21:179-89, (2004)

[54] Patel DM, Patel NM, Patel VF, et al. Floating granules of ranitidine hydrochloride-gelucire 43/01, formulation optimization using factorial design. AAPS Pharm SciTech,8(2):1-7, (2007)

[55] Davis DW. Method of Swallowing a Pill, US Patent No. 3,418,999. Dec 1968.

[56] Kawashima Y. Hollow microspheres for use as a floating controlled drug delivery system in the stomach. J Pharm Sci, 81:135-140, (1992)

[57] Fell JT, Whitehead L and Collett JH. Prolonged Gastric Retention Using Floating Dosage Forms. Pharm Technol, 24:82-90, (2000)

[58] Rosenzweig O, Lavy E, Gati I, et al. Development and in vitro characterization of floating sustained-release drug delivery systems of polyphenols. Drug Deliv, 20:180189, (2013)

[59] Mudie DM, Amidon GL, Amidon GE. Physiological parameters for oral delivery and in vitro testing. Mo Pharm, 7:1388-1405, (2010)

[60] Sakr FM. A programmable drug delivery system for oral administration. Int J Pharm, 184:131-9, (1999)

[61] Michaels AS, Bashwa JD, Zaffaroni A. Integrated Device for Administering Beneficial Drug at Programmed Rate. US Patent No. 3,901,232, 1975.

[62] Hilton AK, Deasy PB. In vitro and in vivo Evaluation of an Oral Sustained Release Floating Dosage Form of Amoxycillin Trihydrate. Int J Pharm, 86:79-88, (1992)

[63] Arrora S, Ali J, Khar RK \& Baboota S. Floating drug delivery systems: A review, AAPS Pharm Sci Tech, 6:372, (2005) 
[64] Sheth PR \& Tossounian J. The Hydrodynamically Balanced System $\left(\mathrm{Hbs}^{\mathrm{TM}}\right)$ : A Novel Drug Delivery System for Oral Use. Drug Dev Ind Pharm, 10:313, (1984)

[65] Bardonnet PL, Faivre V, Pugh WJ, et al. Gastroretentive dosage forms: Overview and special case of Helicobacter pylori. J Control Release, 111:1-18, (2006)

[66] Jain NK; Progress in Controlled and Novel Drug Delivery Systems; First Ed. CBSS. Gopalakrishnan et al; Journal of Pharmaceutical Science and Technology. Publishers and Distributors, New Delhi Bangalore,3(2):84-85, (2004)

[67] Goyal M, Prajapati R, Purohit KK, et al. Floating Drug Delivery System. Journal of Current Pharmaceutical Research, 5(1):7- 18, (2011)

[68] Gattani YS, Kawtikwar PS, Sarkar DM, Int J Chem Tech Res, 1:1, (2009)

[69] Khanam N, Alam MI, Sachan A, et al. Design and characterization of mucoadhesive microspheres of novel NSAID drug using algino-eudragit RS100 system. Der Pharmacia Sinica, 2(5):182-191, (2011)

[70] Whitehead L, Fell JT and Collett JH; Development of a Gastroretentive Dosage form; Eur J Pharm Sci, 4:182, (1996)

[71] Vyas S and Khar RK. Gastro retentive systems Controlled drug Delivery.Vallabh Prakashan, Delhi, India : 197-217, (2006)

[72] Chawla G, Gupta P, Koradia V, et al. A means to address intestinal drug absorption. Pharm Technol, 27:50-68, (2003)

[73] Hauptstein S, Muller C, Dunnhaupt S, et al. Preactivated thiomers: evaluation of gastroretentive minitablets. Int J Pharm, 456:473-479, (2013)

[74] Moes AJ. Gastroretentive Dosage Forms; Crit. Rev. The Drug Carrier System, 10:143- 195, (1993)

[75] Chien YW. Oral Drug Delivery System. Marcel Dekker, New York:139, (1992)
[76] Sharma S and Pawar A. Low Density Multiparticulate System for Pulsatile Release of Meloxicam. Int J Pharm, 313:150-58, (2006)

[77] Kakar S, Batra D, Singh R, et al. Magnetic Microspheres as Magical Novel Drug Delivery System: A review; Journal of acute disease:1-12, (2013)

[78] Klausner EA, Lavy E, Friedman M, Hoffman A. Expandable gastroretentive dosage forms. J Control Release, 90(2):143-62, (2003)

[79] Liu Y, Zhang J, Gao Y, et al. Preparation and evaluation of glyceryl monooleate-coated hollow-bioadhesive microspheres for gastroretentive drug delivery. Int J Pharm, 413(1 2):103-109, (2011)

[80] Sankar R, Jain SK. Development and characterization of gastroretentive sustained-release formulation by combination of swelling and mucoadhesive approach: a mechanistic study. Drug Des Devel Ther,7:1455-1469, (2013)

[81] Chen RN, Ho HO, Yu CY, et al. Development of swelling/floating gastroretentive drug delivery system based on a combination of hydroxyethylcellulose and sodium carboxymethylcellulose for losartan and its clinicalrelevance in healthy volunteers with CYP2C9 polymorphism. Eur J Pharm Sci,39(1-3):82-89, (2010)

[82] Senjoti FG, Mahmood S, Jaffri JM, et al. Design and invitro evaluation of sustained release floating tablets of metformin $\mathrm{HCl}$ based on effervescence and swelling. Iran J Pharm Res, 15:53-70, (2016)

[83] Raut DS and Rohera BD. Formulation, in vitro evaluation and study of variables on tri- layered gastro-retentive delivery system of diltiazem $\mathrm{HCl}$. Drug Dev Ind Pharm, 40:380-389, (2014)

[84] Mandal UK, Chatterjee B and Faria Gias Senjoti FG. Gastro-retentive drug delivery systems and their in vivo success: A recent update. asian journal of pharmaceutical sciences, 11:575-584, (2016)
*Corresponding Author: Nazia Khanam*

Email: nazia.khanam7@gmail.com 